\title{
The application of BIM technology in the construction of Hangzhou Zizhi tunnel
}

\author{
Jianwang Wang ${ }^{1, a}$, Xiaosu Hao ${ }^{1, b}$, Xiang Gao ${ }^{1, c}$
}

\author{
1 The Fifth Engineering Co. Ltd of China Railway First Engineering Group, Baoji 721006, China \\ a56774456@qq.com,,durdgest@qq.com, c41415706@qq.com
}

\begin{abstract}
Keywords: BIM; Zizhi tunnel; model; construction application
Abstract. BIM technology has already got relatively extensive application in the field of domestic architecture, but it is rarely used in the tunnel engineering construction. To solve the problems such as the construction of car cross channel and tunnel subject structure, the construction process control of the whole tunnel project build, the optimization of special construction scheme and the accurate and rapid calculation of quantities, Hangzhou Zizhi tunnel engineering adopts BIM construction application system completed by engineering three-dimensional digitalization technology, and the creation of subject tunnel model including geologic model is completed, five major categories of application points are realized. Combined with three-dimensional geological tool GeoStation and three-dimensional reinforcement software ReStation, specific tunnel construction solution based on BIM application is formed, the innovation and effect in the construction process of Zizhi tunnel is realized, the application value and broad development prospects of BIM technology in the tunnel construction is embodied.
\end{abstract}

\section{Introduction}

As a relatively hot noun in the field of engineering construction at the moment, BIM(Building Information Modeling) has already gradually enabled the entity engineering project as a carrier for the research application of BIM technology, and it has five features of visualization, coordination, simulation, optimization and figuring out[1]. BIM is commonly defined as Building Information Modeling in domestic, it is not a simple process which integrates all kinds of relevant

digitized information in the mode, but is a sort of application of digitized information model, and it is digitized expression of engineering project facility entity and functional characteristics, which can make designer and engineering technicians deal with all kinds of building information accurately, and provide firm foundation for cooperative work[2].

The development of enterprise needs continual innovation and the application of new technology, BIM technology can run through the whole life circle of total engineering project, thus making BIM conduct process control better in planning, design, construction, operation and maintenance[3]. From the investigation of initial construction of this engineering BIM project, it can be known that BIM project is not application precedent of highway tunnel construction in domestic and BIM only has signal application of hydraulic tunnel in the design of power station, it is mainly the application of stress and settlement monitoring combined with hydraulic tunnel three-dimensional model, however, the application research of this highway tunnel BIM project contains the application such as geological analysis of construction stage, engineering budgeting, document management, design change, three-dimensional reinforcement and 3D technical disclosure[4].The application research of Zizhi tunnel BIM technology in the construction will be a milestone in the field.

The research application of BIM technology solves a series of problems in the construction process of this project practically, and the problems such as horse-head rebar filling of tunnel subject model and car cross channel, the calculation of subject quantities and the optimization of special construction scheme are realized one by one[5]. It is undeniable that relative to the application of building, water supply and drainage, heating and ventilation, electromechanical and factories, the application of BIM technology in the tunnel construction is relatively single and the limitation is large, and tunnel has more uncontrollable factors in the construction process as underground construction, therefore, BIM project must be flexible, changeable and dynamic regulated. Through the combination 
of tunnel model generated by accurate parameterization lining section and accurate topography and geological model, and space curve is main line, the dynamic and real-time adjustability of model are realized, meanwhile, the application of basic application points is also realized on this basis[6].

\section{Project Overview}

Zizhi tunnel links Xixi Road and Zijingang to Zhijiang Road and Zhipu Road, the overall length of tunnel is $14.4 \mathrm{~km}$, the construction scale is two-way six lanes, and the main line is composed of three tunnels and two bridges.

China Railway First Engineering Group mainly builds 1\# tunnel exit ( the length of east line is $1400 \mathrm{~m}$, the length of west line is $1427 \mathrm{~m}$ ) and 2\# tunnel entrance (the length of east line is $1828 \mathrm{~m}$, the length of west line is $1823 \mathrm{~m}$ ), the whole length of single hole is 6478 single linear meter. The length of middle-way east line is $62 \mathrm{~m}$, west line is $50 \mathrm{~m}$, moreover, it has two culverts and two ventilating shafts. The route design standard is as follows: city primary road is two-way six lanes; designed speed per hour is $60 \mathrm{~km} / \mathrm{h}$; the clear width of single hole of bored tunnel construction clearance three lanes is $13.5 \mathrm{~m}$, the limited height of lanes is $4.5 \mathrm{~m}$; according to the seismic intensity of 7 degrees, the tunnel structure is designed to strengthen fortification, designed basic seismic acceleration is $0.05 \mathrm{~g}$. The contract cost is 467 million, and the duration is 760 days. Fig. 1 shows the trend schematic of purple tunnel.

BIM technology can work out the hard problems to solve in the traditional tunnel construction and increase construction innovation points, meanwhile, it liberates the workforce, enhances the efficiency of construction and promotes the delicacy management of company[7]. The application of BIM technology is a trend of the industry, and is feasible construction 3D solution, the research we do is all helpful to the process control of the whole project construction, we have got tangible economic benefits based on the application points of BIM technology[8].

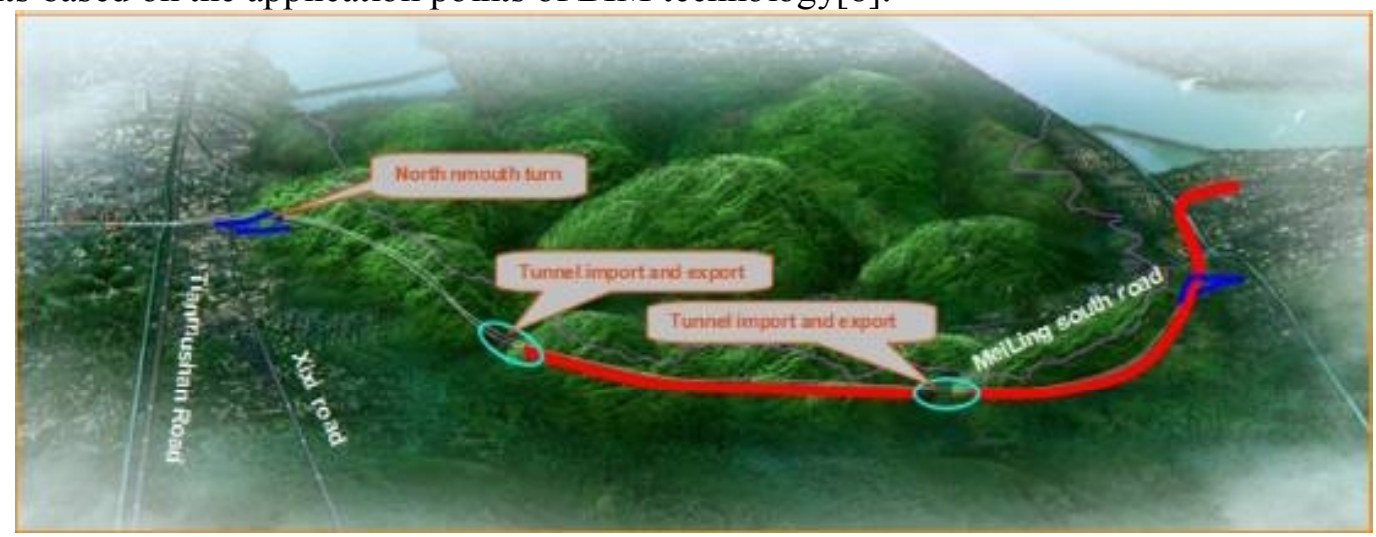

Fig. 1 The trend schematic of purple tunnel

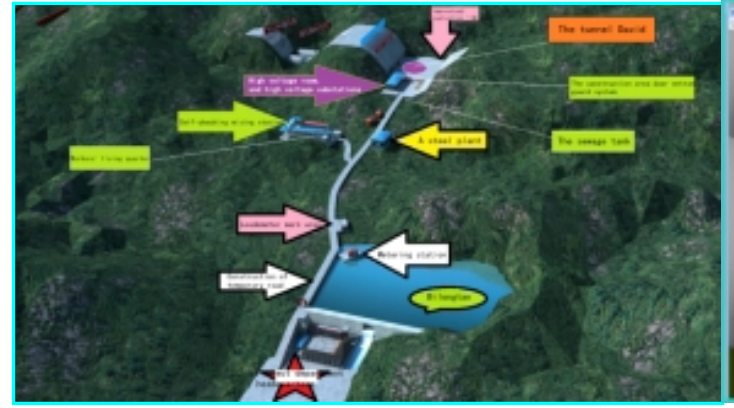

Fig. 2 BIM simulative tunnel construction

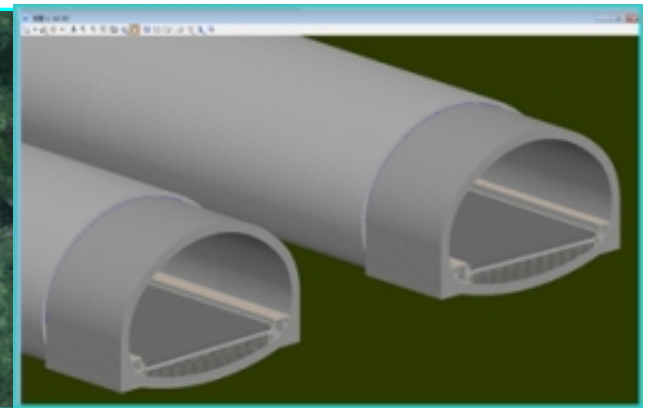

Fig. 3 The main tunnel model site layout

Zizhi tunnel III standard BIM project mainly adopts road design software Bentley PowerCivil, geology tool GeoStation, 3D reinforcement software ReStation, collaborative design platform ProjectWise, basic 3D image platform Bentley Microstation. And it conforms to the following 
principles: the accuracy of model is high, the practicability of engineering is strong, cluster library files can be used in the similar tunnel BIM project repeatedly[9].

Tunnel geologic model, tunnel subject engineering parameterization model, shaft and underground ventilator room parameterization model, people cross channel and car cross channel parameterization model, and subject structure rebar model are mainly completed in this project. Meanwhile, the project results are stored in mobile terminal ipad in the form of i-model, and 3D technical disclosure and the roaming display of model of construction site is realized in coordination with mini projector ( according to tunnel construction practical condition). Fig.2 shows BIM simulative tunnel construction, Fig. 3 shows the main tunnel model.

\section{The Realized Application in Tunnel Construction}

Query Analysis of Topography and Geology Attributes. Topography and geology model is made using geology tool GeoStation researched by East China Investigation \& Design Institute, tunnel subject model is completed using Bentley PowerCivil, then both model are integrated together through PowerCivil, thus Zizhi tunnel III standard geology model is formed, which replaces the traditional 2D geology sectional diagram, and visualization, stereo, guiding construction more intuitively of geology attributes are realized.

Because of the special correlation of tunnel construction and geological conditions of surrounding rocks, the creation of accurate topography and geology model is necessary, so in the modeling beginning of the overall parameterization tunnel model, coordinate system and elevation system are confirmed well at first, elevation information and coordinate information of starting points and terminal points of east and west lines tunnel, elevation and coordinate control points in acciurate combination with geology model are listed. Coordinate system adopts geodetic coordinate system of Hangzhou City, elevation system is national elevation datum of 1985.

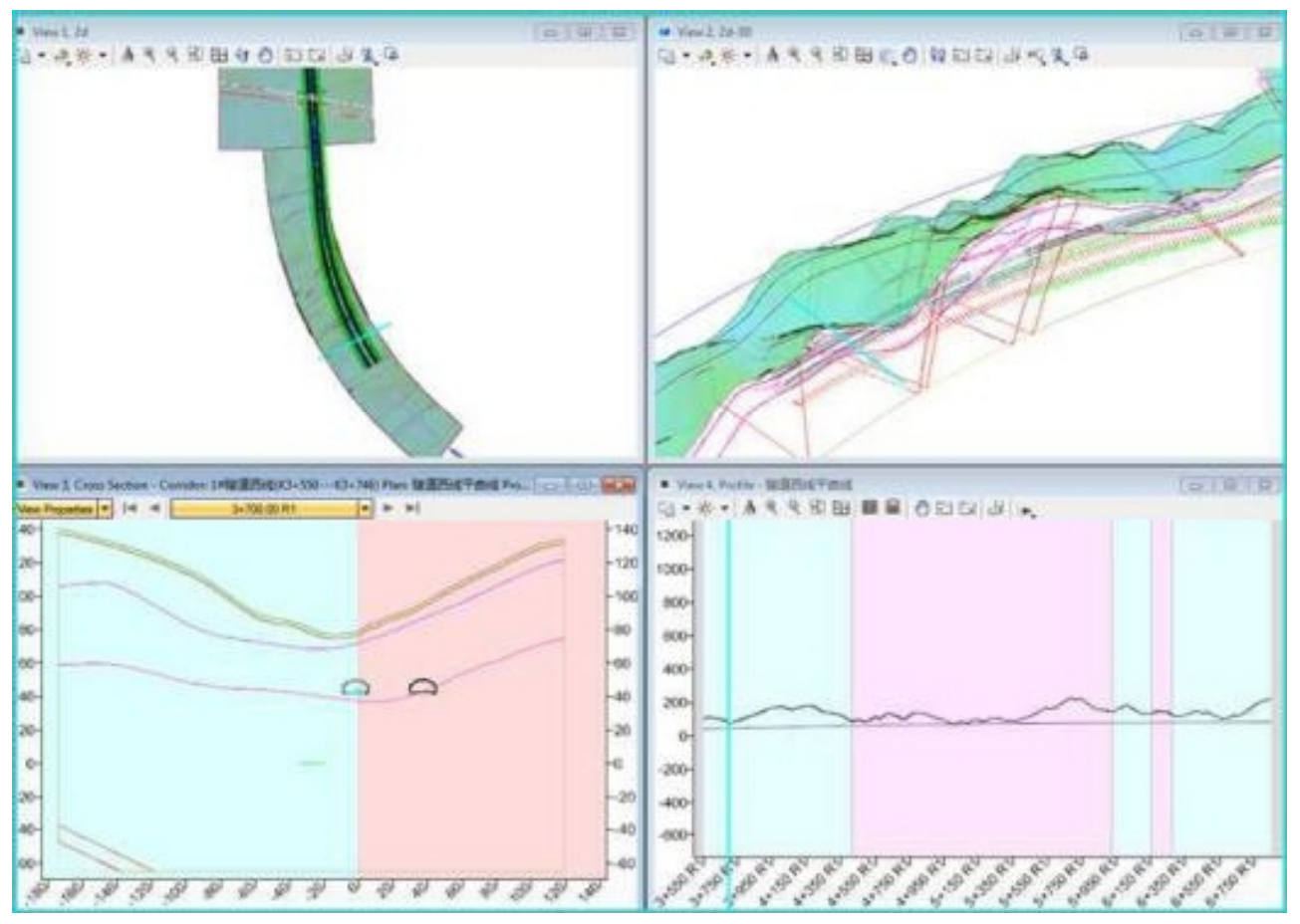

Fig. 4 Geological section of cut tunnel 


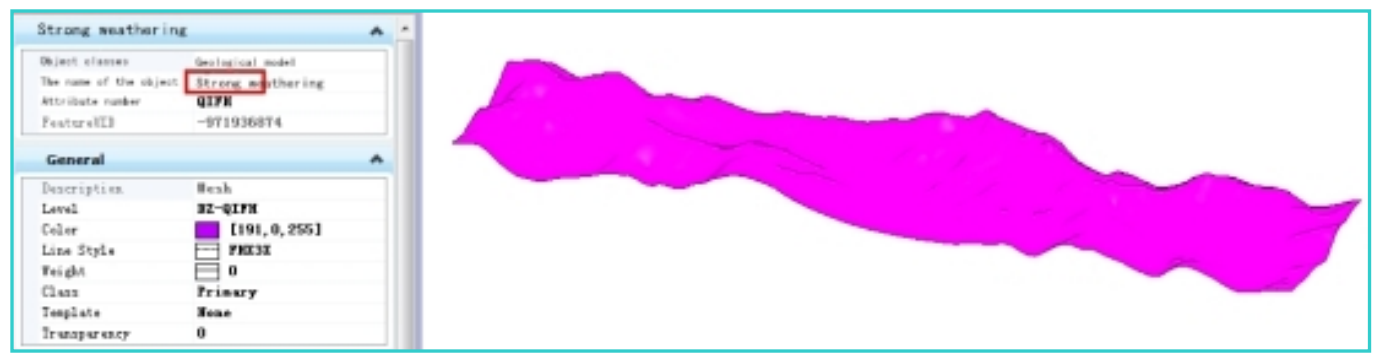

Fig.5 Query of stratum attributes

Three-dimensional model cuts out topographical and geological section based on mileage pile number, thus understanding geology stratiform immediately. The formulation of construction scheme, which is coordinated with subject tunnel model using topography and geology attributes query, is a comprehensive application based on the integration of parameterization geology model and parameterization subject tunnel model. The geological section of cut tunnel is shown in Fig. 4, Query of stratum attributes is shown in Fig. 5.

The whole tunnel subject model keeps linkage with topography and geology model, any mileage pile number of subject model corresponds to topography and geology model of this mileage, and topography and geology section, geological survey information, elevation ( buried depth of tunnel ) data of specific mileage pile number can be exported, meanwhile, the volume of flat excavation and tunnel excavation can also be calculated.

\section{The Management of The Whole Parameterization Model Based on Mileage Pile Number.}

The Management of Mileage Pile Number. Tunnel engineering is not as BIM parameterization model of professional aspects such as building installation engineering in model richness. In the initial period of project construction, simple investigation of application situation in the industry is conducted, domestic tunnel professional field has not conducted integral tunnel professional BIM project[10]. Tunnel model appears one elongated trend as a whole, because the mountain that tunnel passes has different grade division of surrounding rocks, its corresponded tunnel lining timbering type is also different, the whole tunnel parameterization model presents one paragraphed and discontinuous parameterization model, therefore, the management of whole parameterization model based on mileage pile number is put forward at the early stage of project planning process. Fig. 6 shows the management of parameterization model based on mileage pile number.
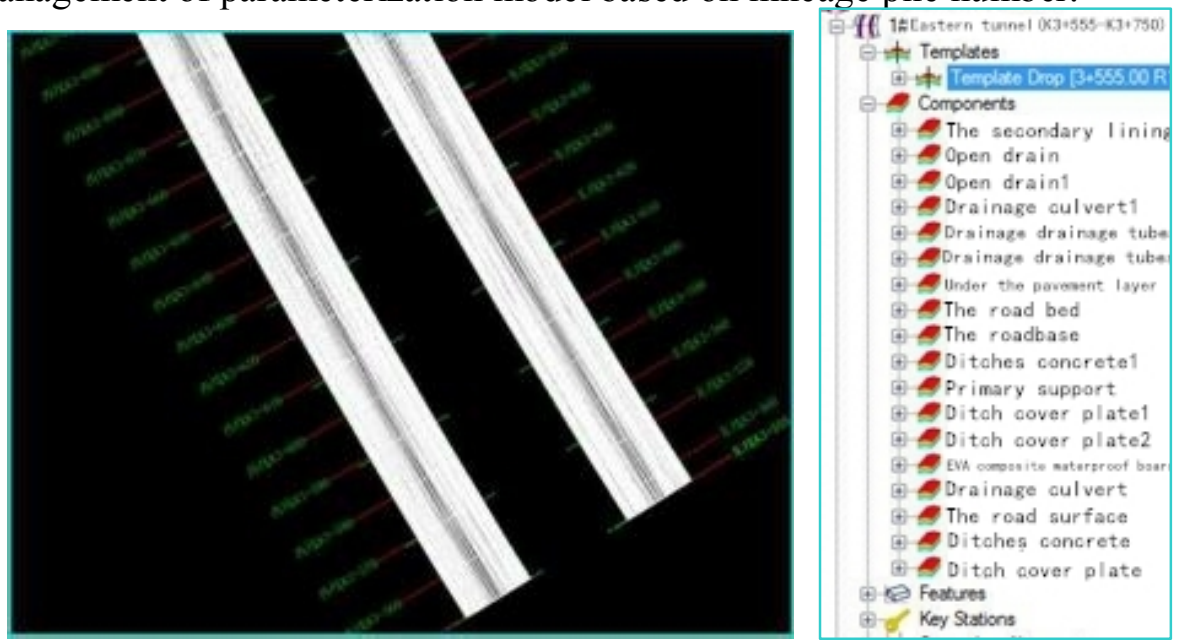

Fig.6 The management of parameterization model based on mileage pile number

According to tunnel space curve of this section, custom attributes of mileage pile number is realized, and mileage pile number is a main line of the whole BIM project, meanwhile, it is the foundation of realizing all kinds of application points[11]. The generation of parameterization section, the definition of branch and subentry model, the given of texture of material, the generation of branch and subentry model, the query of affiliated information of later period, the query of topography and 
geology module information, rapid calculation and accurate statistics of quantities, the generation of material quantity report, the management of subentry parameterization model, the custom space of mileage pile number of BIM project according to practical demand of site, the calculation output of quantities according to needed mileage, and the management of model are all contained[12].

One important innovation point of this project is based on the management mode of mileage pile number, which makes topography and geology model and tunnel subject model integrated together closely and enables the whole project more efficient in the operational process. Meanwhile, in the process of tunnel construction, managing the construction information of whole tunnel using pile number enables BIM technology and practical construction of site to integrate more easily, and it is helpful to the development of all kinds of application points and the coordinated management of whole project.

Rapid Calculation And Accurate Statistics of Quantities. Tunnel subject model is generated according to mileage pile number, and it is related with material system, moreover, in project management platform, all material quantities of this section can be exported in the form of mileage as node according to different lining section, and material quantities report is formed.

According to the progress plan of each month, the demanded amount of material of monthly plan can be calculated rapidly, and it can be related with supplies equipment department and test room, thus the approach plan and test detection plan of material can be given. To a certain degree, the labor workforce is liberated, working efficiency is increased. Table 1 shows the engineering material quantities report.

Table 1 the engineering material quantities report

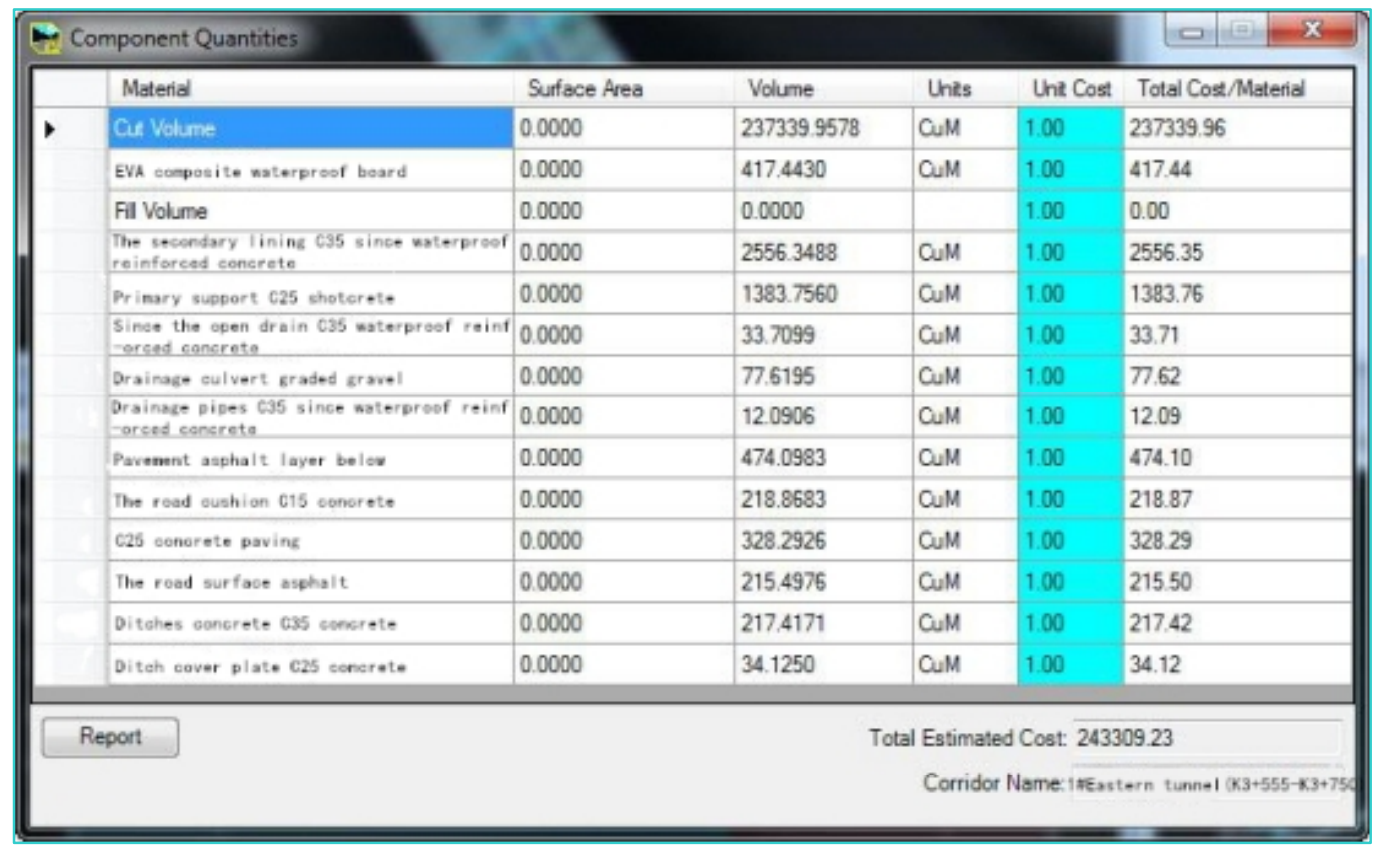

The management of design change and amendment. In the process of tunnel construction, change design of surrounding rock, which is caused by the inaccurate revelation of geological conditions of site surrounding rock, can modify the parameterization section of lining type, thus modifying the mileage section that needs change design and updating parameterization model, which enables model to corresponds to site practical construction condition, and the corresponding design drawing is exported.

Document Integration, Model Association, Real-time query, Real-time update. According to the lining timbering type of different surrounding rock, the drawing files and multimedia material that Zizhi tunnel III standard engineering needs is cleared up, the following can be satisfied: (1) query in directory tree; (2) associated document can also be directly opened in model, and associated document in model can conduct real-time update in the later process of operation and maintenance[13]. 
The linked files of different branch and subentry model of tunnel parameterization model can be opened directly from model to edit ( for example word files ), increased content after editing can be updated into model[14].

3D Reinforcement Application Based on Model. ReStation software is 3D reinforcement software that is researched and developed independently by East China Institute, 3D parameterization reinforcement of purple tunnel III standard subject structure is completed using this tool. Secondary lining, inverted arch, people cross channel, car cross channel, the connected portion of cross channel and tunnel subject are all contained. Fig. 7 shows 3D rebar model- secondary lining rebar, S3- Vd rebar.
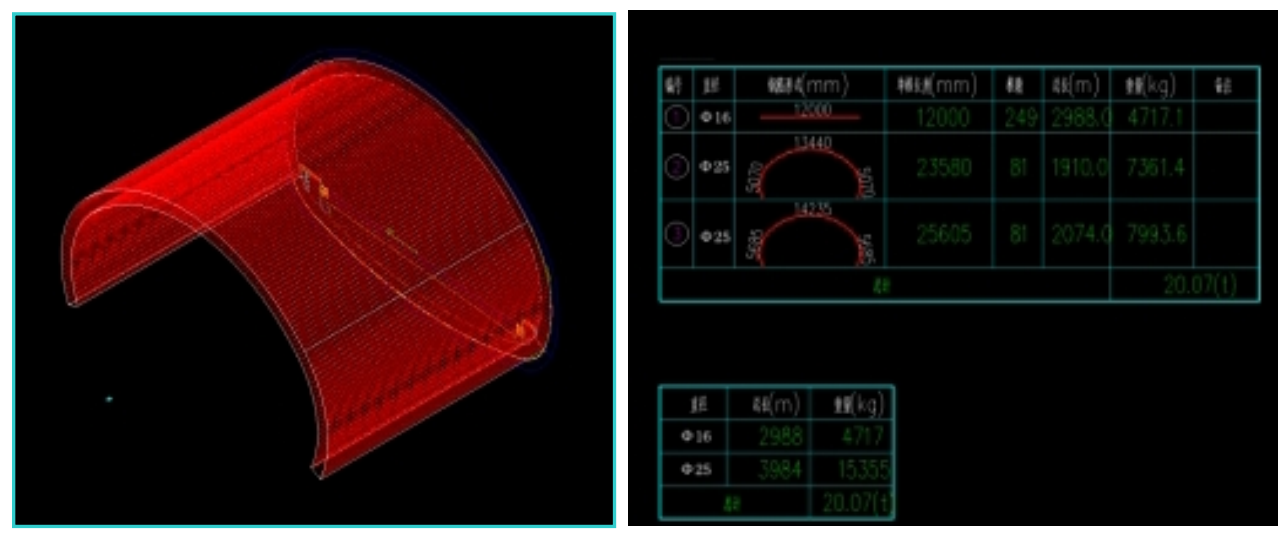

Fig. 7 3D rebar model- secondary lining rebar, S3-V d rebar

Secondary lining construction of people cross channel and car cross channel is one difficulty ( the span is large, the condition of surrounding rocks is inferior), including the colligation of rebar, the pouring of lining concrete. To control the cost, reduce the waste of rebar and increase the colligation efficiency of secondary lining rebar, using application module and rebar module of BIM model, specific model and reinforcement of the connected portion of tunnel subject and car cross channel is done, and accurate filling of site rebar is guided.

Realizing 3D Technical Disclosure and Model Roaming in The Form of i-model and PDF. 3D technical disclosure and model roaming are realized in the form of I-model and 3D PDF mode that are printed by PowerCivil. Each parameterization model is translated into above two formats, and stored into mobile terminal Ipad and computer terminal, moreover, model and the corresponding 3D technical disclosure can be made alone according to specific demand, and site 3D technical disclosure is realized combined with special configured mini projector[10].

Mobile terminal model roaming mainly employs software Bentley Navigator to walk freely in model, to look over model and the affiliated attributes in an all-round way, compared with computer terminal, the visualization degree of mobile terminal model is higher, and mobile terminal has operation sense[15]. Ipad model roaming is shown Fig.8.
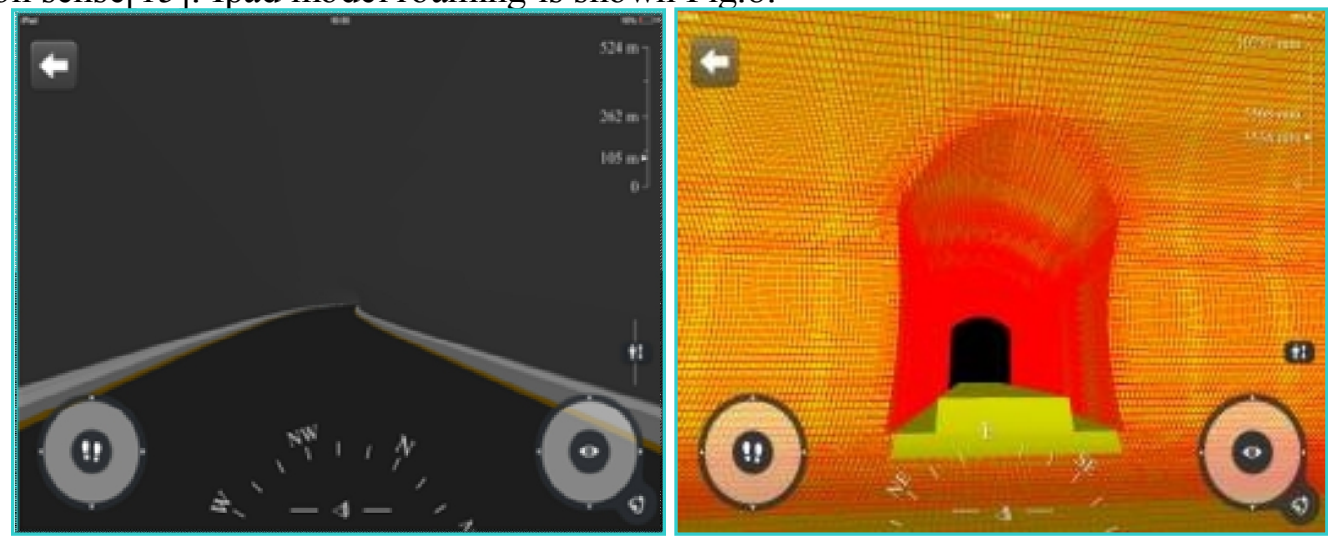

Fig.8 Ipad model roaming 


\section{The Achieved Main Benefits Applying BIM Technology in This Project}

Economic Benefits. The construction of connected portion of car, people cross channel and tunnel subject structure. The construction of secondary lining of cross channel is a difficulty, it contains the colligation of rebar (the length of each rebar at the connected portion is not the same), the pouring of concrete. To control the cost, reduce the unnecessary waste of rebar, increase the colligation efficiency of secondary lining, site employs application module and rebar module of model, specific model and reinforcement of the connected portion of tunnel subject and car cross channel is done. The corresponding rebar table is generated after finishing reinforcement, this table includes the form of each rebar, the length of single rebar, the number, overall length and weight of the same type rebar. Fig. 9 shows the model and reinforcement of cross portion

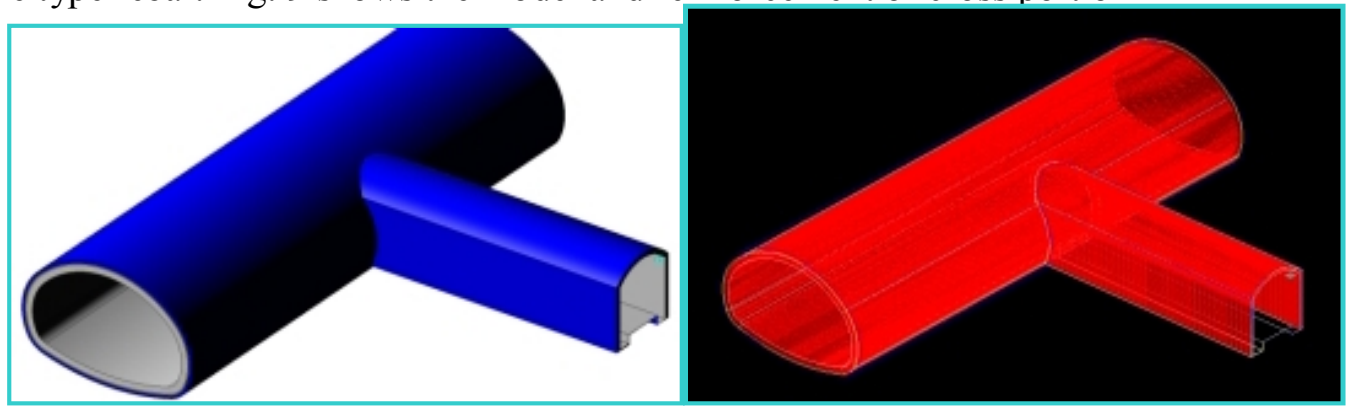

Fig. 9 The model and reinforcement of cross portion

Taking the car traffic as an example, if construction is done according to the traditional scheme, passing 7\# car cross channel needs 15 days, however, the reinforcement optimization of the connected portion of cross channel and tunnel subject structure is conducted using ReStation 3D reinforcement software, $8 \#$ car cross channel only takes 5 days, the construction cost is saved in the process of car traffic construction after BIM technology optimization. Fig. 10 shows the model, reinforcement of cross portion and site $3 \mathrm{D}$ technical disclosure.
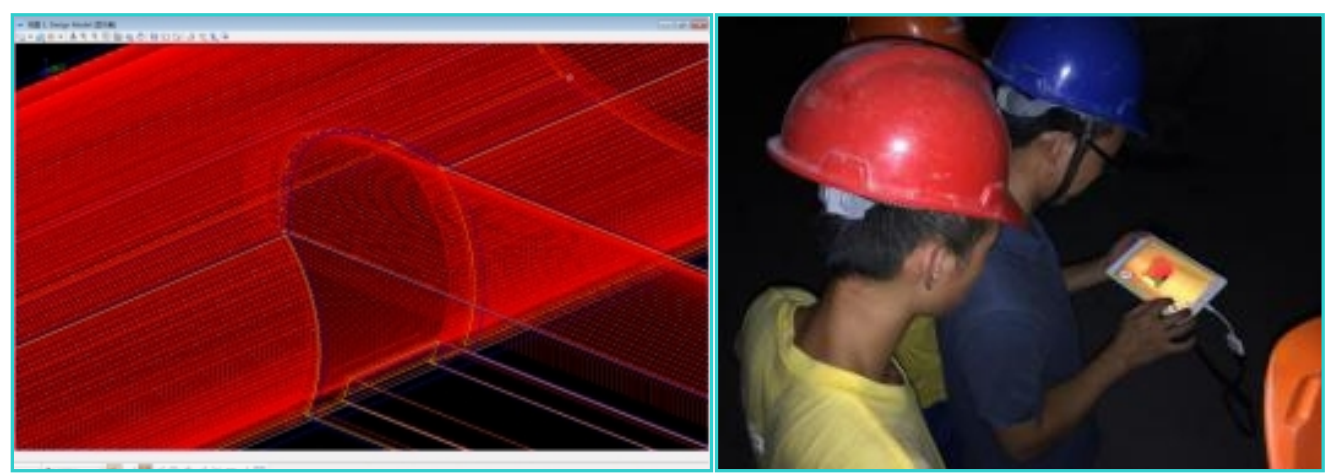

Fig. 10 The model, reinforcement of cross portion and site 3D technical disclosure

Labor cost is as follows: the pay of rebar setter is 240 yuan per day; calculating the rebar dosage of average each one car passing head horse can save 0.8 ton steels; the purchasing price of steels is 3500 per ton, therefore, the reduced cost in the process of car passing construction after using BIM technology optimization is: $3500 \times 0.8 \times 8 \times 2+4 \times 240 \times(15-5)=54400$ yuan. So there are six car passing, the saved cost is: $54400 \times 6=326400$ yuan.

The optimization of construction scheme of two shallow buried outcrop sections of west line 2\# tunnel.K5+075 $\sim \mathrm{K} 5+090(15 \mathrm{~m})$ of $2 \#$ tunnel west line is negative buried depth outcrop section, $\mathrm{K} 5+170 \sim \mathrm{K} 5+185(15 \mathrm{~m})$ is shallow buried section, and 2\# tunnel is located in national forest park of western hill, dragon well tea trees are everywhere at the col of two shallow buried outcrop section of $2 \#$ tunnel west line, original design scheme is requisitioning tea garden outside the red line and forest land to build temporary transportation shortcut road, then reinforced concrete pre-supporting system arch is done in the outcrop section. But because of the difficulty of temporary ground, and the 
investment is large, the construction of two shallow buried outcrop sections, the felling of forest and woods, and requisitioning dragon well tea trees are all very difficult, and it needs State Forestry Bureau to deal with relevant procedures, but the construction days are urgently needed.

Through BIM construction simulation and combined with geological conditions of surrounding rocks of this section, scheme comparison is conducted, and the half-covered and half-dug construction scheme is established, namely, outcrop and exiting the hole is forced, then the pit tunnel that is constructed well is made as construction transportation channel, making the tunnel roof while doing the excavation, then the secondary entrance of hole is constructed normally. Fig. 11 shows the construction of outcrop section of $2 \#$ tunnel west line

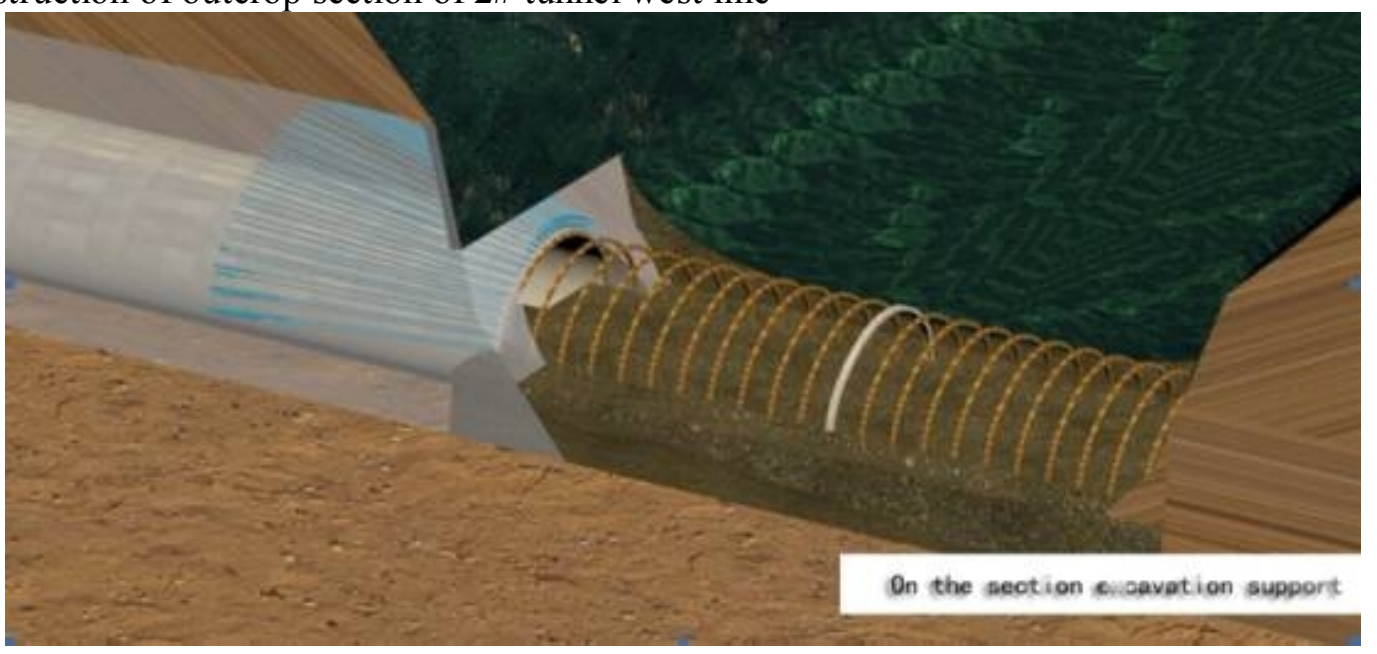

Fig.11 The construction of outcrop section of 2\# tunnel west line

Through topography simulation technology of BIM, the construction simulation of dangerous topography such as the position of exit and entrance of hole is conducted in advance, practical construction time shortens the construction time, reduces the investment of labor workforce, material resources, financial resources, and saves the cost of building temporary shortcut road and construction site by requisitioning forest land and tea tree land in protection area, so saved capital is 1.35 million, and saved construction days are 32 days. Table 2 shows the comparison table of capital investment of outcrop section after using BIM technology.

Table 2 The comparison table of capital investment of outcrop section after using BIM technology

\begin{tabular}{|c|c|c|}
\hline \multirow{2}{*}{ Project } & \multicolumn{2}{|c|}{ Construction money (million) } \\
\cline { 2 - 3 } & $\begin{array}{c}\text { Original construction } \\
\text { scheme }\end{array}$ & $\begin{array}{c}\text { Construction scheme after } \\
\text { BIM technology }\end{array}$ \\
\hline $\begin{array}{c}\text { Requisition of forest land } \\
\text { and tea tree land }\end{array}$ & 0.82 & 0.12 \\
\hline Building of shortcut road & 0.16 & 0 \\
\hline Investment of materials & 0.48 & 0.50 \\
\hline Construction wage & 0.16 & 0.10 \\
\hline Returning green of & 0.26 & 0.11 \\
\hline temporary land & 2.18 & 0.83 \\
\hline Sum & & \\
\hline
\end{tabular}


Talents Benefits. By the participation of overall process of BIM technology application in this project, training mode of theory combined with practical project promotes individual technological level of BIM technicians. The awareness and level of BIM application of all project department technicians are promoted in the form of from points to surface, thus laying the foundation for further deepening BIM technology application, meanwhile, tunnel BIM application achievements have won the second prize in the national contest of BIM application for 2014, studying and observing BIM projects of different major by the contest, the horizon of technicians is broadened, and innovation is stimulated.

In the excavation process of tunnel, the real-time query of geological conditions of surrounding rocks around tunnel face can be conducted applying geology module, which offers corresponding basis of geological conditions of surrounding rocks for forepoling and excavation footage, thus making safety construction of tunnel building be in a controlled state.

At present, the time of safety production of project is 502 days; province, city and associate organization observe 12 times, and one construction site of standardization model that has innovation and effect is created.

\section{Conclusion and Prospects}

At present, BIM technology application of tunnel major is little in domestic, main basic application points of tunnel engineering application BIM technology is different from BIM technology application of building, water supply and drainage, heating and ventilation, electromechanical and factories. The application of BIM technology of bridges, tunnel and highway is also gradually developed following the example of building in the BIM boom. Because of different major, in the process of implement, the whole BIM project plan must be conducted according to the feature of one's own major. The excavation of tunnel subject engineering is closely related with surrounding rocks, they must be united in a system, rather than playing one's own function independently, this engineering BIM project based on the associated system, is practically to implement each application point, and it can be adjusted dynamically according to site practical situation, thus basically achieving the desired effect. On the question of the calculation of quantities and rebar filling of main hole and car cross channel horesehead, the labor workforce is liberated, the construction efficiency is increased, and the control of cost is realized; accurate and efficient systemization query and the simulation and optimization of scheme are realized in geology module; these application which has strong practicability and creates certain benefits is the basis of consolidation and innovation.

Although BIM technology has acquired better effect and benefit in project application at present, there are still some aspects to be improved, for example, how to combine the construction organization design and timely implement of specific scheme compilation, the fusion of site tunnel monitoring measurement information and BIM system.

Based on this, this project BIM technology will be further developed and applied later: the secondary exploitation of mobile terminal ipad, including rapid query according to mileage pile number and edit all the information of this mileage, taking photos at the scene and imputing the construction photos; further optimizing reinforcement simulation, reducing the waste of rebar, controlling the construction cost; the correlation of 3D simulation attached with $4 \mathrm{G}$ orientation and practical monitoring measurement, establishing early warning mechanism of all kinds of controlled points; the correlation of model and force analysis software, the simulation of stress change of surrounding rocks, providing more reference information for optimizing the construction scheme.

\section{Acknowledgements}

This work was the Scientific Research Program of China railway engineering corporation (2014A-061-3.1): the application of BIM technology in Hangzhou ZIzhi tunnel construction; The $p$ articipated research project of 2014 A category (2014 A-063): the application research of comprehe 
nsive energy consumption analysis and water pressure blasting technology of tunnel borehole-blast ing method construction.

\section{References}

[1] Zhang Jian-ping, Cao Ming. A 4D construction management system based on IFC standard snd engineering information model[J]. Engineering Mechanics, 2005(S1): 200-210.

[2] Zhang Yang. Study on construction engineering information integration and management based on BIM[D]. Beijing: Tsinghua University, 2009.

[3] Yang D, Eastman C M. A rule-based subset generation method for product data models[J]. Computer-aided Civil and Infrastructure Engineering, 2007, 22(2): 133-148.

[4] Liang Xiong, Lu Ming, Zhang Jian-ping. Integration of as-built and as -designed models for positioning control during construction[J]. Automation in Construction, 2011, 20(3): 234-246.

[5] Tao Qing, Wang Hong-chun. Present situation analysis and countermeasure research on engineering project management information[J]. Journal of Beijing Institute of Civil Engineering and Architecture, 2007, 23(1): 77-80.

[6] Shi Zhen, Feng Dong-mei, He Mei. Applying the managing information system in the project management and several suggestions[J]. Value Engineering, 2008, (3): 92-94.

[7] Yu Chuan-fei. Architectural design and construction with computer integrated information system[M]. Beijing: China Architecture \& Building Press, 2008: 35-350.

[8] Chen Qian, Zhang Hou. Discussion on the conception and application of BIM[J]. Value Engineering, 2012, (23): 61-62.

[9] He Guan-pei, Li Gang. What is the thing called BIM in the end[M]. Beijing: China Architecture \& Building Press, 2011: 57-64.

[10] Xia Chao-yang, Han Chuan-feng. PM-ASP model of web-based construction project management system[J]. Construction Management Modernization, 2005, (3): 5-8.

[11] Gong Xiao-lin, Xu You-quan. Analysis of the project management information[J]. Shanxi Architecture, 2006, 32(2): 188-189.

[12] He Guan-pei. BIM Pandect[M]. Beijing: China Architecture \& Building Press, 2011: 23-25.

[13] Ge Qing. The First Dimension of BIM[M]. Beijing: China Architecture \& Building Press, 2013: $100-120$.

[14] Zhang Jian-ping, Li Ding, Lin Jia-rui. Application of BIM in engineering construction[J]. Construction Technology, 2012, 41(371): 10-14.

[15] Xu You-quan, Liu Xin. Study on flat organization structure of the large construction projects based on BIM[J]. Journal of Engineering Management, 2013, 27(1): 44-47. 